\title{
Reduction of the Nitro Group to Amine by Hydroiodic Acid to Synthesize o-Aminophenol Derivatives as Putative Degradative Markers of Neuromelanin
}

\author{
Kazumasa Wakamatsu ${ }^{1, *}$, Hitomi Tanaka ${ }^{1}$, Keisuke Tabuchi ${ }^{1}$, Makoto Ojika ${ }^{2}$, Fabio A. Zucca ${ }^{3}$, \\ Luigi Zecca $^{3}$ and Shosuke Ito ${ }^{1}$
}

1 Department of Chemistry, Fujita Health University School of Health Sciences, Toyoake, Aichi 470-1192, Japan; E-Mails: hmatsuoka@u-gifu-ms.ac.jp (H.T.);

82013103@fujita-hu.ac.jp (K.T.); sito@fujita-hu.ac.jp (S.I.)

2 Department of Applied Molecular Biosciences, Graduate School of Bioagricultural Sciences, Nagoya University, Furo-cho, Chikusa-ku, Nagoya 464-8601, Japan;

E-Mail: ojika@agr.nagoya-u.ac.jp

3 Institute of Biomedical Technologies, National Research Council of Italy, Via Cervi, 93, Segrate, Milano 20090, Italy; E-Mails: fabio.zucca@itb.cnr.it (F.A.Z.); luigi.zecca@itb.cnr.it (L.Z.)

* Author to whom correspondence should be addressed; E-Mail: kwaka@fujita-hu.ac.jp; Tel.: +81-562-93-2518; Fax: +81-562-93-4595.

Received: 4 May 2014; in revised form: 5 June 2014 / Accepted: 6 June 2014 /

Published: 16 June 2014

\begin{abstract}
Neuromelanin (NM) is produced in dopaminergic neurons of the substantia nigra (SN) and in noradrenergic neurons of the locus coeruleus (LC). The synthesis of $\mathrm{NM}$ in those neurons is a component of brain aging and there is the evidence that this pigment can be involved in the pathogenesis of neurodegenerative diseases such as Parkinson's disease. $\mathrm{NM}$ is believed to derive from the oxidative polymerization of dopamine (DA) or norepinephrine (NE) with the participation of cysteine, dolichols and proteins. However, there are still unknown aspects in the chemical structure of NM from SN (SN-NM) and LC (LC-NM). In this study, we designed a new method to synthesize $o$-aminophenol compounds as putative degradation products of catecholamines and their metabolites which may be incorporated into NM. Those compounds are aminohydroxyphenylethylamine (AHPEA) isomers, aminohydroxyphenylacetic acid (AHPAA) isomers and aminohydroxyethylbenzene (AHEB) isomers, which are expected to arise from DA or NE, 3,4-dihydroxyphenylacetic acid (DOPAC) or 3,4-dihydroxyphenylmandelic acid (DOMA) and 3,4-dihydroxyphenylethanol (DOPE) or 3,4-dihydroxyphenylethyleneglycol (DOPEG), respectively. These $o$-aminophenol
\end{abstract}


compounds were synthesized by the nitration of phenol derivatives followed by reduction with hydroiodic acid (HI), and they could be identified by HPLC in HI hydrolysates of SN-NM and LC-NM. This degradative approach by HI hydrolysis allows the identification of catecholic precursors unique to SN-NM and LC-NM, which are present in catecholaminergic neurons.

Keywords: neuromelanin; aminohydroxyphenylethylamine; aminohydroxyphenylacetic acid; aminohydroxyethylbenzene; Parkinson's disease; HI reduction

\section{Introduction}

There are two chemically distinct types of peripheral melanins, black to brown pigments called eumelanin, and yellow to reddish-brown pigments called pheomelanin [1-3]. Eumelanin is derived from the oxidative polymerization of 5,6-dihydroxyindole (DHI) and 5,6-dihydroxyindole-2-carboxylic acid (DHICA), while pheomelanin consists of benzothiazine and benzothiazole units arising from cysteinyl-3,4-dihydroxyphenylalanine (Cys-DOPA) isomers. On the other hand, neuromelanin (NM) consists of black to brown pigments mainly found in neurons of the substantia nigra (SN) and locus coeruleus (LC) in the central nervous system of human and other mammalian species [4]. Previous studies from our group and other groups have shown that NM consists of complex polymers derived from eumelanic DHI and pheomelanic benzothiazine units along with additional aliphatic and proteic components [5-8]. NM accumulates during normal aging in neurons of different brain areas but, interestingly, SN and LC that are the main target regions of Parkinson's disease (PD) are those with the highest pigment concentrations $[9,10]$. NM is formed by the oxidation of catecholamines, dopamine (DA) and norepinephrine (NE), in the presence of cysteine (Cys). The synthesis of NMs in the various regions of the human brain is an important protective process because the melanic components are generated through the removal of reactive or toxic $o$-quinones that would otherwise cause neurotoxicity. Another important aspect of the protective role of NM is the ability to bind toxic metals forming stable complexes thereby blocking their toxicity [10]. On the other hand, due to its biochemical properties, NM has also been discussed as a critical factor underlying neuronal vulnerability in PD [5,9-11]. In PD the NM released by degenerating neurons can cause microglia activation and neurodegeneration. In cell culture and in vivo studies it was shown that human NM induces microglia activation and neuronal death [11-14]. In SN and LC, catecholamine neurons containing NM highly express major histocompatibility complex-I which triggers neuronal death mediated by cytotoxic T cells [15].

To study the structure and function of peripheral (cutaneous) melanin, we have developed several chemical methods to quantify eumelanin and pheomelanin [16-19]. Alkaline $\mathrm{H}_{2} \mathrm{O}_{2}$ oxidation affords pyrrole-2,3,5-tricarboxylic acid (PTCA) as a eumelanin marker and thiazole-2,4,5-tricarboxylic acid (TTCA) as a pheomelanin marker. Pheomelanin can also be analyzed as 4-amino-3-hydroxyphenylalanine (4-AHP) after hydroiodic acid (HI) hydrolysis. To study the structure and function of NM, we used HPLC to analyze 4-amino-3-hydroxyphenylethylamine (4-AHPEA) and 3-amino-4-hydroxyphenylethylamine (3-AHPEA) after HI hydrolysis, in addition to pyrrole-2,3-dicarboxylic acid (PDCA), TTCA and 
thiazole-4,5-dicarboxylic acid (TDCA) after $\mathrm{H}_{2} \mathrm{O}_{2}$ oxidation. Several markers analyzed by HPLC are currently used for melanin analysis, but only two, PTCA and 3-amino-4-hydroxyphenylalanine (3-AHP), are commercially available. Thus, most of those HPLC markers must be prepared by simple chemical processes [20]. 4-AHP, a major degradation product of pheomelanin upon HI hydrolysis, can be prepared by HI hydrolysis of $5-S$-cysteinyldopa-melanin [20,21]. However, we found that this amino acid can be more readily obtained in a $100 \mathrm{mg}$ scale by the nitration of commercially available $m$-tyrosine followed by HI reduction of the resulting 3-hydroxy-4-nitrophenylalanine along with other possible isomers [20]. Authentic samples of 4-AHPEA and 3-AHPEA used in previous studies were prepared by reductive HI hydrolysis of 5-S-cysteinyldopamine-melanin (5-S-CysDA-melanin) and 2-S-cysteinyldopamine-melanin (2-S-CysDA-melanin) according to established methods [6,7,22,23]. However, this method requires the preparation of 5-S-CysDA and 2-S-CysDA in advance followed by their oxidation to melanin, which is time-consuming and requires the skillful separation of 5-S-CysDA and 2-S-CysDA. Thus, an alternative chemical method was needed to prepare these $o$-aminophenol derivatives in more convenient and generally applicable manner. In this study, we developed a convenient reduction of the nitro group to amine with HI to synthesize $o$-aminophenol derivatives as putative degradative markers of human NM.

\section{Results and Discussion}

\subsection{Chemistry}

The biosynthesis of NM, oxidative polymerization of catecholamines, suggests the possibility that various catecholic metabolites would also participate in NM genesis (Scheme 1). In addition to 1 and 2, 3,4-dihydroxyphenylalanine (DOPA, 3), 3,4-dihydroxyphenylacetic acid (DOPAC, 4), 3,4-dihydroxymandelic acid (DOMA, 5), 3,4-dihydroxyphenylethanol (DOPE, 6) and 3,4-dihydroxyphenylethyleneglycol (DOPEG, 7) can be incorporated into NM. These compounds are metabolites of $\mathbf{1}$ and $\mathbf{2}$ formed by oxidative deamination by monoamine oxidase followed by oxidation/reduction. We also reported that melanin pigments derived from Cys-DOPA can be identified in NMs isolated from other important regions of human brain, such as putamen, premotor cortex, and cerebellum [10]. We have already established methods to determine eumelanin and pheomelanin in peripheral (cutaneous) melanin that can be used for the characterization of NM [7,8,16-20]. These methods are based on melanin degradation by alkaline $\mathrm{H}_{2} \mathrm{O}_{2}$ oxidation and reductive $\mathrm{HI}$ hydrolysis. Upon $\mathrm{HI}$ hydrolysis, NM afforded 4-AHPEA 8c and its isomer 3-AHPEA 9c along with benzothiazole derivatives. These $o$-aminophenol compounds are derived from Cys-DA and Cys-NE melanins. HI hydrolysis of NMs, derived from the above catechol derivatives, 1-7, is expected to afford the corresponding $o$-aminophenol derivatives, AHPEAs (8c and 9c), aminohydroxyphenylacetic acid (AHPAAs, 10c and 11c), and aminohydroxyethylbenzene (AHEBs, 12c and 13c) (Scheme 2). 
Scheme 1. Possible participation in NM biosynthesis of various catecholic metabolites known to be present in various brain regions of the human brain. Purple circles depict NM accumulation in neurons of the $\mathrm{SN}$. (O) represents oxidants.

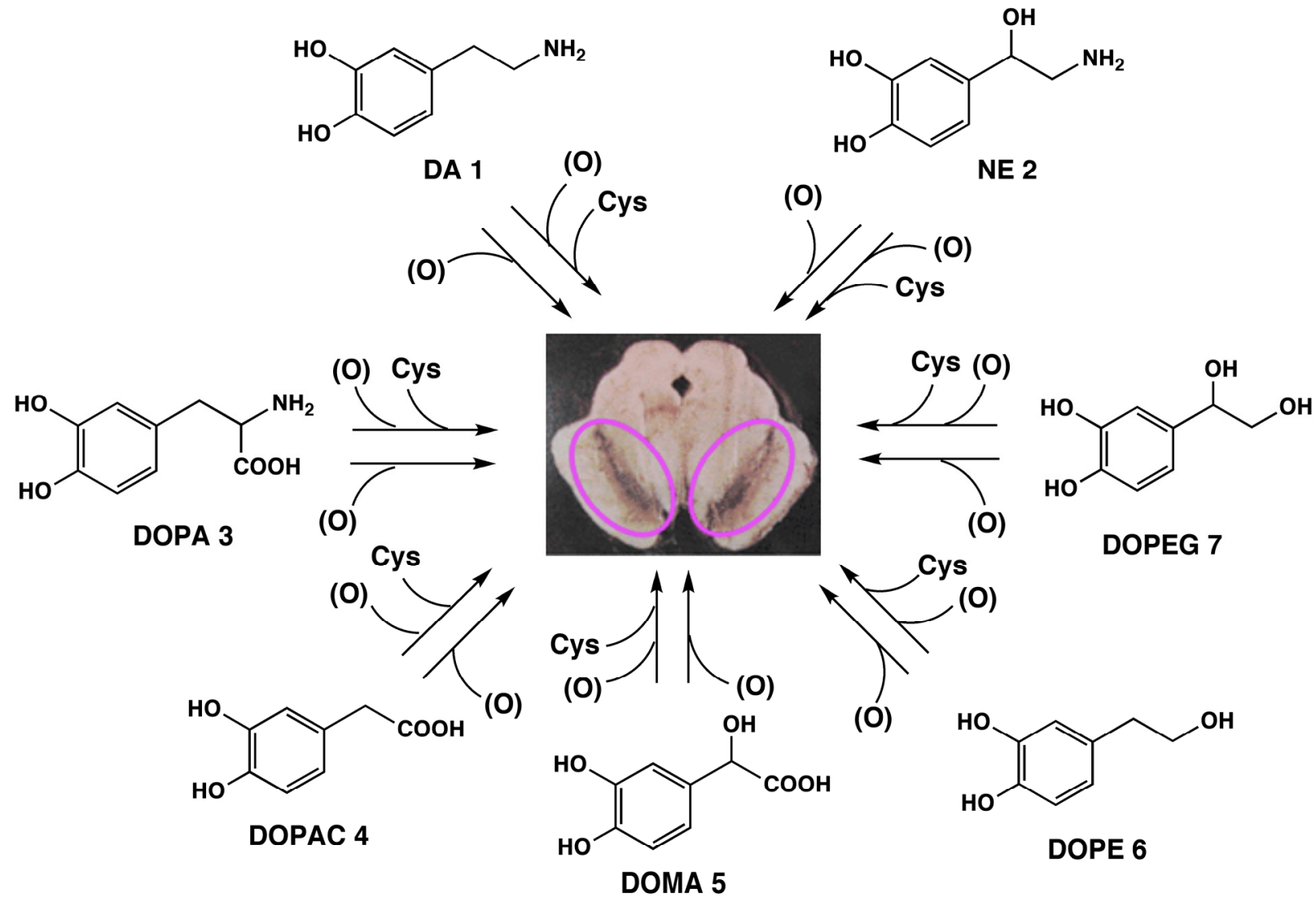

Scheme 2. Possible degradation products afforded by the reductive HI hydrolysis of human NM.

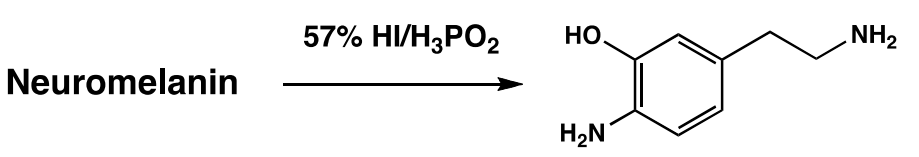

4-AHPEA 8c

(and 3-AHPEA 9c)<smiles>Nc1ccc(CC(=O)O)cc1O</smiles>

4-AHPAA 10c

(and 3-AHPAA 11c)<smiles>CCc1ccc(N)c(O)c1</smiles>

4-AHEB 12C

(and 3-AHEB 13c)

Thus, we planned a synthetic scheme involving the $o$-nitration of the corresponding phenols with $60 \% \mathrm{HNO}_{3}$ followed by reduction with $57 \% \mathrm{HI}$. The desired $o$-aminophenols c were separated on a cation exchange resin and purified by recrystallization of the $\mathrm{HCl}$ salts (Scheme 3 ).

The synthesis of the $o$-aminophenol derivatives c comprises a series of two known reactions (Scheme 3). The first step (aromatic nitration) and the second step (reduction of the nitro group to amine) are common to all products c. In the first step, the nitration of phenols a was carried out by $60 \% \mathrm{HNO}_{3}$ at room temperature for $10 \mathrm{~min}$-overnight followed by separation of the nitrated phenols with a cation exchange resin or extraction with ethyl acetate. $o$ - and $p$-Oriented nitrophenol isomers were subjected to reduction of the nitro group without further purification. The nitration of $p$-substituted phenols afforded only $o$-nitrophenol derivatives $\mathbf{b}$, so the yields were nearly quantitative. On the other hand, the nitration of $m$-substituted phenols afforded isomeric $o$ - and $p$-oriented 
nitrophenols and dinitrophenol derivatives. Thus, the yields of the target compounds were much lower than those from $p$-substituted phenol derivatives.

Scheme 3. Synthetic scheme of the nitration of $m$ - and $p$-substituted phenol derivatives followed by reduction of the nitro group to amine with reductive HI hydrolysis. Parenthesis is a yield.
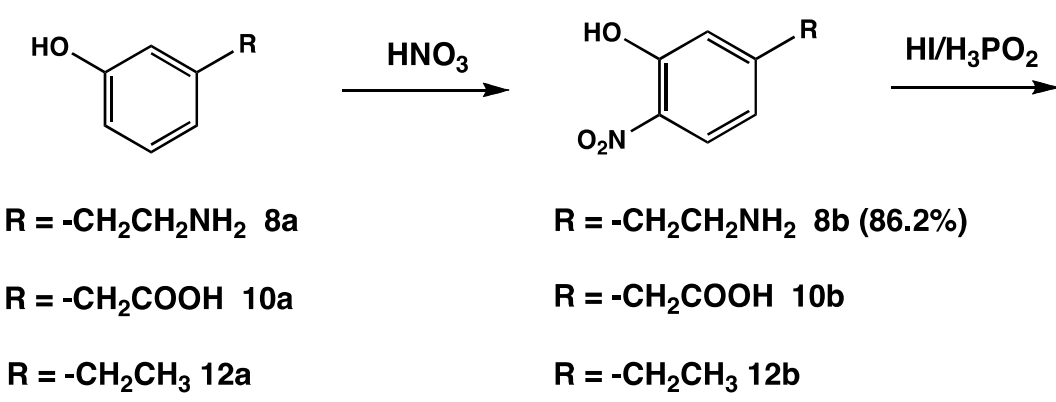<smiles>Nc1ccc(P)cc1O</smiles>

$$
\begin{aligned}
& \mathrm{R}=-\mathrm{CH}_{2} \mathrm{CH}_{2} \mathrm{NH}_{2} \quad 8 \mathrm{~b}(86.2 \%) \\
& \mathrm{R}=-\mathrm{CH}_{2} \mathrm{COOH} 10 \mathrm{~b} \\
& \mathrm{R}=-\mathrm{CH}_{2} \mathrm{CH}_{3} 12 \mathrm{~b}
\end{aligned}
$$

$\mathrm{R}=-\mathrm{CH}_{2} \mathrm{CH}_{2} \mathrm{NH}_{2} 8 \mathrm{c}(13.0 \%)$

$\mathrm{R}=-\mathrm{CH}_{2} \mathrm{COOH} 10 \mathrm{c}(12.2 \%$ by 2 steps $)$

$\mathrm{R}=-\mathrm{CH}_{2} \mathrm{CH}_{3} \mathrm{12c}(4.7 \%$ by 2 steps $)$
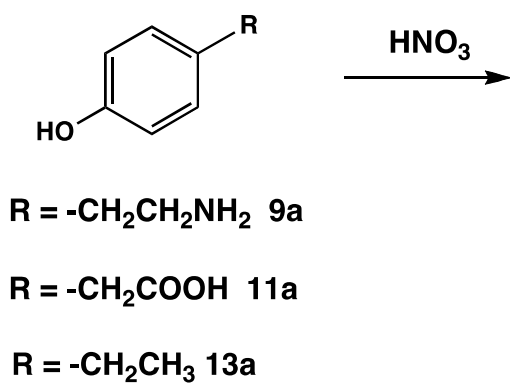<smiles>[R]c1ccc(O)c([N+](=O)[O-])c1</smiles>

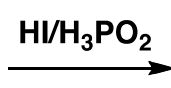

$R=-\mathrm{CH}_{2} \mathrm{CH}_{2} \mathrm{NH}_{2}$ 9b (90.3\%)

$\mathrm{R}=-\mathrm{CH}_{2} \mathrm{COOH} 11 \mathrm{~b}(63.9 \%)$

$\mathrm{R}=-\mathrm{CH}_{2} \mathrm{CH}_{3} \mathbf{1 3 b}$<smiles>[R]c1ccc(O)c(N)c1</smiles>

$\mathrm{R}=-\mathrm{CH}_{2} \mathrm{CH}_{2} \mathrm{NH}_{2} \mathrm{9c}(93.4 \%)$

$\mathrm{R}=-\mathrm{CH}_{2} \mathrm{COOH} 11 \mathrm{c}(81.2 \%)$

$\mathrm{R}=-\mathrm{CH}_{2} \mathrm{CH}_{3} 13 \mathrm{c}(42.4 \%$ by 2 steps $)$

In the literature, several methods for the reduction of nitro groups to amines have been reported. Aromatic amines are known to be produced by catalytic hydrogenation under continuous high pressure [24-27]. Nitro compounds can also be reduced to amines in good yields with iron and hydrochloric acid in the Béchamp reaction [25], which is the oldest commercial process for preparing amines, and is still used in the dyestuff industry. The reduction of $o$-nitrophenol $\mathbf{b}$ to $o$-aminophenol $\mathbf{c}$ must be done under a reductive environment because aminophenol is susceptible to oxidation. Thus, we have developed the $\mathrm{HI} / \mathrm{H}_{3} \mathrm{PO}_{2}$ method for reduction of the nitro group. $\mathrm{HI}$ has a high acidity and potential reducing ability. Compared with other reduction methods in the literature, this method is easy because the work-up after the reaction requires only the removal of HI under reduced pressure without further filtration of the catalyst or extraction of the solution. After the evaporation of HI, the reaction mixture was chromatographed on an ion-exchange resin. The target compound as the $\mathrm{HCl}$ salt was further recrystallized from ethanol plus ether. 3-Amino-4-hydroxyphenyl derivatives 9c, 11c and 13c were obtained in moderate to high overall yields $(84 \%, 52 \%$ and $42 \%$, respectively). On the other hand, 4-amino-3-hydroxyphenyl derivatives 8c, 10c and 12c were obtained in relatively low overall yields $(11 \%, 12 \%$ and $4.7 \%$, respectively), because of the production of other possible isomers and diamino derivatives. The poor yield of $12 \mathrm{c}$ may be due to the low purity $(80 \%)$ of the starting material, 3-ethylphenol (12a) which contains the isomers 4-ethylphenol (13a) and 2-ethylphenol making the separation of the desired product difficult. As the isolation of $\mathbf{1 0 b}, \mathbf{1 2} \mathbf{b}$, and $\mathbf{1 3 b}$ were difficult, the reaction products were subjected to the following reaction without the further purification. 


\subsection{Chemical Analyses of NM Isolated from the SN and LC of Human Brain}

The reductive HI hydrolysis of NM isolated from the SN and LC of human midbrains was performed, and the degradation products were identified by HPLC using newly synthesized $o$-aminophenol compounds c as standards (Table 1). It should be emphasized that LC-NM has never been studied before by chemical degradative methods, which have been mainly employed on NM isolated from other areas of human brain $[6,7,10]$. We have previously reported that the chemical degradation of SN with HI affords $\mathbf{8 c}$ and $\mathbf{9 c}$ in high yields, and $\mathbf{1 4} \mathbf{c}$ and 15c in low yield [6,7,10]. AHP isomers 14c and 15c are derived from Cys-DOPA melanin [18]. In this study, we could detect AHEBs for the first time as a mixture of $12 \mathrm{c}$ and 13c, and AHPAA isomers 10c and 11c in SN-NM. In LC-NM, we could also now detect 8c, 9c, 10c and 11c together with AHEBs 12c and 13c. These results suggest that SN-NM and LC-NM are derived not only from DA 1 and NE 2, but also from DOPA 3, DOPAC 4, DOMA 5, DOPE 6 and DOPEG 7, because AHPEA isomers 8c, 9c, AHPAA isomers 10c, 11c, AHEB isomers 12c, 13c and AHP isomers 14c, 15c are expected to arise from DA 1 or NE 2, DOPAC 4 or DOMA 5, DOPE 6 or DOPEG 7 and DOPA 3, respectively. We could also detect DA 1, DOPA 3, and DOPAC 4 after HI hydrolysis. This result indicated that the protein-bound derivatives of DA 1, DOPA 3, and DOPAC 4 were incorporated into SN-NM and LC-NM [10].

Table 1. Chemical characterization with reductive HI hydrolysis of human NM isolated from SN and LC tissues (values in $\mathrm{ng} / \mathrm{mg}$ ).

\begin{tabular}{|c|c|c|c|c|c|c|c|c|c|c|}
\hline Sample & $\begin{array}{l}\text { DA } \\
\text { (1) }\end{array}$ & $\begin{array}{c}\text { DOPA } \\
\text { (3) }\end{array}$ & $\begin{array}{c}\text { DOPAC } \\
\text { (4) }\end{array}$ & $\begin{array}{c}\text { 4-AHPEA } \\
\text { (8c) }\end{array}$ & $\begin{array}{c}\text { 3-AHPEA } \\
\text { (9c) }\end{array}$ & $\begin{array}{c}\text { 4-AHPAA } \\
\text { (10c) }\end{array}$ & $\begin{array}{c}\text { 3-AHPAA } \\
\text { (11c) }\end{array}$ & $\begin{array}{c}\text { AHEBs } \\
(12 c, 13 c)\end{array}$ & $\begin{array}{c}\text { 4-AHP } \\
\text { (14c) }\end{array}$ & $\begin{array}{r}\text { 3-AHP } \\
\text { (15c) }\end{array}$ \\
\hline SN-NM & 1,224 & 722 & 161 & 428 & 588 & 735 & 571 & 32 & 62 & 66 \\
\hline LC-NM & 955 & 624 & 368 & 806 & 695 & 596 & 310 & 75 & 52 & 114 \\
\hline
\end{tabular}

Values were obtained in a single determination.

\section{Experimental Section}

\subsection{General Information}

${ }^{1} \mathrm{H}-\mathrm{NMR}$ spectra (400 MHz for ${ }^{1} \mathrm{H}-\mathrm{NMR}$ and $100 \mathrm{MHz}$ for ${ }^{13} \mathrm{C}-\mathrm{NMR}$ ) were recorded on a Bruker AVANCE 400 spectrometer and are reported as the chemical shifts $\delta$ (ppm) downfield from sodium 2,2-dimethyl-2-silapentane-5-sulfonate (DSS) or $t$-butyl alcohol used as an internal reference. Coupling constants $(J)$ are expressed in $\mathrm{Hz}$ and signals are expressed as s (singlet), d (doublet) or $\mathrm{t}$ (triplet). Elemental analyses were carried out by the Organic Elemental Analysis Research Center (Kyoto University, Japan). For ion-exchange column chromatography, a Dowex 50W-X2 (200-400 mesh) column was used. UV spectrometry was monitored using a JASCO V-630 UV-VIS spectrometer (JASCO Co., Tokyo, Japan). HPLC systems consisted of a JASCO 880-PU pump, a JASCO $\mathrm{C}_{18}$ column (JASCO Catecholpak; $4.6 \mathrm{~mm} \times 150 \mathrm{~mm} ; 7 \mu \mathrm{m}$ particle size) and an EICOM ECD-300 electrochemical detector (EICOM, Kyoto, Japan), and a Shiseido $\mathrm{C}_{18}$ column (Shiseido Capcell Pak MG; $4.6 \mathrm{~mm} \times 250 \mathrm{~mm} ; 5 \mu \mathrm{m}$ particle size) and a JASCO UV detector (JASCO Co.). DA 1, NE 2, DOMA 5, DOPEG 7, 3-amino-4-hydroxyphenylalanine (3-aminotyrosine, 15c), 57\% $\mathrm{HI}$ and mushroom tyrosinase $(4,276 \mathrm{U} / \mathrm{mg})$ were purchased from Sigma Aldrich Japan (Tokyo, Japan), 
3-ethylphenol 12a (80\% purity), 4-ethylphenol 13a and DOPE 6 were purchased from Tokyo Chemical Industry Co. (Tokyo, Japan), and 3-hydroxyphenylethylamine 8a, 4-hydroxyphenylethylamine 9a, 3-hydroxyphenylacetic acid 10a, 4-hydroxyphenylacetic acid 11a and Dowex 50W-X2 were purchased from Wako Pure Chemical Industries, Ltd. (Osaka, Japan). All other chemicals were of the highest purity available.

Reductive HI hydrolysis was performed as described previously $[6,7,18,20]$. Briefly, a mixture of $100 \mu \mathrm{L}$ suspension of a sample (containing $0.1 \mathrm{mg}$ melanin), $30 \mu \mathrm{L} 30 \% \mathrm{H}_{3} \mathrm{PO}_{2}$ and $500 \mu \mathrm{L} 57 \% \mathrm{HI}$ was heated in a screw-capped tube at $130{ }^{\circ} \mathrm{C}$ for $20 \mathrm{~h}$, after which the mixture was cooled. An aliquot $(100 \mu \mathrm{L})$ of each hydrolysate was transferred to a test tube and evaporated to dryness using a vacuum pump connected to a dry ice-cooled vacuum trap and two filter flasks containing $\mathrm{NaOH}$ pellets. The residue was dissolved in $200 \mu \mathrm{L} 0.1 \mathrm{M} \mathrm{HCl}$. An aliquot $(10 \mu \mathrm{L})$ of each solution was analyzed by HPLC as described in Section 3.2.

Human NMs were isolated from SN and LC tissues and used in the experiments as described previously $[6,7,10,28]$. This study was approved by the Ethical Committee of the National Research Council of Italy-Institute of Biomedical Technologies (Segrate, Milan, Italy) and was carried out in agreement with the Policy of the National Research Council of Italy. SN-NM was isolated from a pool of five subjects with age range 73-85 years old. LC-NM was isolated from a pool of 35 subjects with age range $62-94$ years old.

\subsection{General Procedure for the Synthesis of 4-Amino-3-hydroxy and 3-Amino-4-hydroxyphenyl}

\section{Derivatives 8c-13c}

An appropriate phenol compound 8a-13a $(1 \mathrm{mmol})$ was mixed with $60 \% \mathrm{HNO}_{3}(4.8 \mathrm{mmol})$. The resulting suspension was stirred at room temperature for $10 \mathrm{~min}$ for $\mathbf{8 a}$ and $9 \mathbf{a}$, for $30 \mathrm{~min}$ for $\mathbf{1 0 a}, \mathbf{1 2 a}$ and 13a, or overnight for 11a, leading eventually to an intensively dark red solution. HPLC analysis confirmed the absence of starting material and the presence of 3 major products corresponding most likely to nitro derivatives resulting from nitration at the $o$ - and $p$-positions of the hydroxy group from the $m$-substituted phenols 8a, 10a and 12a, but only one product from the $p$-substituted phenols 9a, 11a and 13a. The crude nitrophenol $8 \mathbf{b}$ or $9 \mathbf{b}$ was diluted with water $(20 \mathrm{~mL})$ and applied onto a Dowex 50W-X2 (200-400 mesh) column $\left(1.5 \mathrm{~cm} \times 6 \mathrm{~cm}, \mathrm{H}^{+}\right.$form, equilibrated with water). The column was washed with water $(100 \mathrm{~mL})$ and then the product was eluted with $2 \mathrm{M} \mathrm{HCl}$ (20 mL/fraction). Fractions containing the target compound were combined and evaporated to dryness to give a yellow powder. After the nitration of phenols $10 a, 12 a$ and 13a, the reaction mixture $(\mathbf{1 0 b}$, 12b and 13b) was diluted with $\mathrm{H}_{2} \mathrm{O}(20 \mathrm{~mL})$ and extracted with ethyl acetate $(2 \times 100 \mathrm{~mL})$. The combined organic extract was washed with water $(2 \times 50 \mathrm{~mL})$, dried with $\mathrm{Na}_{2} \mathrm{SO}_{4}$ and evaporated under reduced pressure. The nitration of $\mathbf{1 1 a}$ afforded $\mathbf{1 1 b}$ as an orange powder in the reaction mixture. After the filtration, the powder was washed with water and dried under reduced pressure to give a dark red powder $\mathbf{1 1 b}$.

The nitrophenol compounds $\mathbf{8 b}-\mathbf{1 3 b}$ were then heated under reflux with $57 \% \mathrm{HI}(10 \mathrm{~mL})$ in the presence of $30 \% \mathrm{H}_{3} \mathrm{PO}_{2}(1.0 \mathrm{~mL})$. After $60 \mathrm{~min}$, HPLC analysis confirmed the absence of the nitrated compounds and the appearance of products corresponding most likely to amino derivatives resulting from reduction to amine at the $o$ - (and $p$-) positions of the hydroxy group. The mixture was evaporated 
to dryness, taken up in $0.1 \mathrm{M} \mathrm{HCl}(3 \mathrm{~mL})$ and chromatographed on a Dowex 50W-X2 (200-400 mesh) column $(1.8 \mathrm{~cm} \times 31 \mathrm{~cm}$, equilibrated and eluted with $2 \mathrm{M} \mathrm{HCl})$. Fractions of $20 \mathrm{~mL}$ were collected and analyzed by UV spectrophotometry $(200-400 \mathrm{~nm})$ and by HPLC. The analytical conditions of HPLC are described in Section 3.2. After fractions of the target compound were collected, recrystallization of compounds $\mathbf{8 c}-\mathbf{1 3 c}$ from ethanol $(5 \mathrm{~mL})$ plus ether $(25 \mathrm{~mL})$ and compound $\mathbf{1 4 c}$ from $6 \mathrm{M} \mathrm{HCl}(3 \mathrm{~mL})$ plus acetone $(60 \mathrm{~mL})$ gave colorless crystals as $\mathrm{HCl}$ salts.

\subsection{HPLC Analyses of Aminophenols $\mathbf{8 c - 1 3 c}$}

The HPLC system consisted of a JASCO $\mathrm{C}_{18}$ column (JASCO Catecholpak; $4.6 \mathrm{~mm} \times 150 \mathrm{~mm}$; $7 \mu \mathrm{m}$ particle size) and an EICOM ECD-300 electrochemical detector. The mobile phase used was $0.1 \mathrm{M}$ sodium citrate buffer, $\mathrm{pH} 3.0$, containing $1 \mathrm{mM}$ sodium octanesulfonate and $0.1 \mathrm{mM}$ $\mathrm{Na}_{2}$ EDTA: methanol, 92: $8(\mathrm{v} / \mathrm{v})$ at $40{ }^{\circ} \mathrm{C}$ at a flow rate of $0.7 \mathrm{~mL} / \mathrm{min}$. The electrochemical detector was set at $+500 \mathrm{mV}$ versus the $\mathrm{Ag} / \mathrm{AgCl}$ reference electrode. The retention times were 9.2, 9.7, 15.2, $16.2,93.2$ and $93.5 \mathrm{~min}$ for $\mathbf{1 0 c}, \mathbf{1 1 c}, \mathbf{8 c}, \mathbf{9 c}, \mathbf{1 2 c}$ and $\mathbf{1 3 c}$, respectively. The retention times for 12c and 13c were shortened to 43.6 min using the above buffer: methanol, 80:20. It was impossible to separate 12c and $13 \mathbf{c}$ under the above HPLC conditions.

4-Amino-3-hydroxyphenylethylamine (4-AHPEA) (8c). Colorless crystals. Yield: 12\%. Purity 99\% by HPLC. ${ }^{1} \mathrm{H}-\mathrm{NMR}$ (DCl): $\delta=2.85$ (t, $\left.2 \mathrm{H}, J=8.0 \mathrm{~Hz}, \mathrm{CH}_{2}\right), 3.15$ (t, $\left.2 \mathrm{H}, J=8.0 \mathrm{~Hz}, \mathrm{CH}_{2}\right), 6.80(\mathrm{~d}, 1 \mathrm{H}$, $J=4.0 \mathrm{~Hz}, \mathrm{CH}), 6.86(\mathrm{~s}, 1 \mathrm{H}, \mathrm{CH}), 7.19(\mathrm{~d}, 1 \mathrm{H}, J=4.0 \mathrm{~Hz}, \mathrm{CH}) .{ }^{13} \mathrm{C}-\mathrm{NMR}\left(\mathrm{D}_{2} \mathrm{O}, t\right.$-butyl alcohol was added as an internal reference): $\delta=28.34,38.96,115.45,115.98,119.60,122.90,137.74,148.68$. Elemental analysis: calculated for $\mathrm{C}_{8} \mathrm{H}_{12} \mathrm{O}_{1} \mathrm{~N}_{2} .2 \mathrm{HCl}$. C, 42.68\%; H, 6.27\%; N, $12.44 \%$; Cl, 31.50\%; found: C, 43.25\%; H, 6.07\%; N, 12.43\%; Cl, 32.76\%. UV (0.1 M HCl) $\lambda_{\max } 274 \mathrm{~nm}(\varepsilon 2240)$ and $221 \mathrm{~nm}$ $(\varepsilon 6,700)$.

3-Amino-4-hydroxyphenylethylamine (3-AHPEA) (9c). Colorless crystals. Yield: 84\%. Purity 99\% by HPLC. ${ }^{1} \mathrm{H}-\mathrm{NMR}$ (DCl): $\delta=2.83\left(\mathrm{t}, 2 \mathrm{H}, J=8.0 \mathrm{~Hz}, \mathrm{CH}_{2}\right), 3.13\left(\mathrm{t}, 2 \mathrm{H}, J=8.0 \mathrm{~Hz}, \mathrm{CH}_{2}\right), 6.93(\mathrm{~d}, 1 \mathrm{H}$, $J=12.0 \mathrm{~Hz}, \mathrm{CH}), 7.13(\mathrm{~s}, 1 \mathrm{H}, \mathrm{CH}), 7.15(\mathrm{~d}, 1 \mathrm{H}, J=12.0 \mathrm{~Hz}, \mathrm{CH}) .{ }^{13} \mathrm{C}-\mathrm{NMR}\left(\mathrm{D}_{2} \mathrm{O}, t\right.$-butyl alcohol was added as an internal reference): $\delta=28.99,39.87,116.24,117.60,123.55,128.25,129.95,148.29$. Elemental analysis: calculated for $\mathrm{C}_{8} \mathrm{H}_{12} \mathrm{O}_{1} \mathrm{~N}_{2} .2 \mathrm{HCl}$. C, 42.68\%; H, 6.27\%; N, $12.44 \%$; Cl, 31.50\%; found: C, 42.29\%; H, 6.17\%; N, 12.30\%; Cl, 32.08\%. UV (0.1 M HCl) $\lambda_{\max } 276 \mathrm{~nm}(\varepsilon 1,970)$ and $221 \mathrm{~nm}(\varepsilon 7,720)$.

4-Amino-3-hydroxyphenylacetic Acid (4-AHPAA) (10c). Colorless crystals. Yield: 12\%. Purity 99\% by HPLC. ${ }^{1} \mathrm{H}-\mathrm{NMR}(\mathrm{DCl}): \delta=3.71\left(\mathrm{~s}, 2 \mathrm{H}, \mathrm{CH}_{2}\right), 6.92(\mathrm{~d}, 1 \mathrm{H}, J=8.0 \mathrm{~Hz}, \mathrm{CH}), 7.00(\mathrm{~s}, 1 \mathrm{H}, \mathrm{CH}), 7.33(\mathrm{~d}$, $1 \mathrm{H}, J=8.0 \mathrm{~Hz}, \mathrm{CH})$. Elemental analysis: calculated for $\mathrm{C}_{7} \mathrm{H}_{9} \mathrm{O}_{3} \mathrm{~N}_{1} . \mathrm{HCl} . \mathrm{C}, 47.19 \% ; \mathrm{H}, 4.95 \%$; $\mathrm{N}, 6.88 \%$; $\mathrm{Cl}, 17.41 \%$; found: $\mathrm{C}, 46.95 \% ; \mathrm{H}, 5.07 \% ; \mathrm{N}, 6.60 \% ; \mathrm{Cl}, 17.52 \%$. UV (0.1 M HCl) $\lambda_{\max }$ $274 \mathrm{~nm}(\varepsilon 2,110)$ and $212 \mathrm{~nm}(\varepsilon 6,350)$.

3-Amino-4-hydroxyphenylacetic Acid (3-AHPAA) (11c). Colorless crystals. Yield: 52\%. Purity 99\% by HPLC. ${ }^{1} \mathrm{H}-\mathrm{NMR}(\mathrm{DCl}): \delta=3.71\left(\mathrm{~s}, 2 \mathrm{H}, \mathrm{CH}_{2}\right), 7.05(\mathrm{~d}, 1 \mathrm{H}, J=8.4 \mathrm{~Hz}, \mathrm{CH}), 7.27$ (d, 1H, $\left.J=8.4 \mathrm{~Hz}\right)$, $7.28(\mathrm{~s}, 1 \mathrm{H})$. Elemental analysis: calculated for $\mathrm{C}_{7} \mathrm{H}_{9} \mathrm{O}_{3} \mathrm{~N}_{1} . \mathrm{HCl} . \mathrm{C}, 47.19 \%$; H, 4.95\%; N, 6.88\%; 
Cl, 17.41\%; found: C, 46.09\%; H, 4.89\%; N, 6.64\%; Cl, 18.05\%. UV (0.1 M HCl) $\lambda_{\max } 276 \mathrm{~nm}$ $(\varepsilon 1,880)$ and $212 \mathrm{~nm}(\varepsilon 7,060)$.

4-Amino-3-hydroxyethylbenzene (4-AHEB) (12c). Colorless crystals. Yield: 4.7\%. Purity 95\% by ${ }^{1} \mathrm{H}-\mathrm{NMR} .{ }^{1} \mathrm{H}-\mathrm{NMR}(\mathrm{DCl}): \delta=1.18\left(\mathrm{t}, 3 \mathrm{H}, J=7.6 \mathrm{~Hz}, \mathrm{CH}_{3}\right), 2.61\left(\mathrm{dd}, 2 \mathrm{H}, J=7.6,7.6 \mathrm{~Hz}, \mathrm{CH}_{2}\right), 6.91$ $(\mathrm{dd}, 1 \mathrm{H}, J=8.0,1.6 \mathrm{~Hz}, \mathrm{CH}), 6.95(\mathrm{~d}, 1 \mathrm{H}, J=1.6 \mathrm{~Hz}, \mathrm{CH}), 7.27(\mathrm{~d}, 1 \mathrm{H}, J=8.0 \mathrm{~Hz}, \mathrm{CH}) .{ }^{13} \mathrm{C}-\mathrm{NMR}$ (DCl): $\delta=16.57,29.78,116.83,117.56,121.79,125.61,149.62,151.51$. Elemental analysis: calculated for $\mathrm{C}_{8} \mathrm{H}_{11} \mathrm{O}_{1} \mathrm{~N}_{1} . \mathrm{HCl} .1 / 4 \mathrm{H}_{2} \mathrm{O}$. C, 53.94\%; $\mathrm{H}, 7.07 \% ; \mathrm{N}, 7.86 \% ; \mathrm{Cl}, 19.90 \%$; found: $\mathrm{C}, 54.07 \%$; $\mathrm{H}, 6.79 \%$; N, 7.88\%; Cl, 19.33\%. UV (0.1 M HCl) $\lambda_{\max } 272 \mathrm{~nm}(\varepsilon 2,250)$ and $212 \mathrm{~nm}(\varepsilon 6,750)$.

3-Amino-4-hydroxyethylbenzene (3-AHEB) (13c). Colorless crystals. Yield: 42\%. Purity 99\% by HPLC. ${ }^{1} \mathrm{H}-\mathrm{NMR}(\mathrm{DCl}): \delta=1.18\left(\mathrm{t}, 3 \mathrm{H}, J=7.6 \mathrm{~Hz}, \mathrm{CH}_{3}\right), 2.60\left(\mathrm{dd}, 2 \mathrm{H}, J=7.6,7.6 \mathrm{~Hz}, \mathrm{CH}_{2}\right), 7.00$ (d, $1 \mathrm{H}, J=8.0 \mathrm{~Hz}, \mathrm{CH}), 7.22(\mathrm{~s}, 1 \mathrm{H}, \mathrm{CH}), 7.24(\mathrm{~d}, 1 \mathrm{H}, J=8.0 \mathrm{~Hz}, \mathrm{CH})$. Elemental analysis: calculated for $\mathrm{C}_{8} \mathrm{H}_{11} \mathrm{O}_{1} \mathrm{~N}_{1} . \mathrm{HCl}$. C, 55.33\%; H, 6.98\%; N, 8.07\%; Cl, 20.41\%; found: C, 55.16\%; H, 6.91\%; N, $8.07 \% ; \mathrm{Cl}, 20.64 \%$. UV (0.1 M HCl) $\lambda_{\max } 277 \mathrm{~nm}(\varepsilon 2,270)$ and $220 \mathrm{~nm}(\varepsilon 7,610)$.

4-Amino-3-hydroxyphenylalanine (4-AHP) (14c). Colorless crystals. Yield: 23\%. Purity 99\% by HPLC. ${ }^{1} \mathrm{H}-\mathrm{NMR}(\mathrm{DCl}): \delta=3.11\left(\mathrm{~m}, 2 \mathrm{H}, \mathrm{CH}_{2}\right), 4.07(\mathrm{~m}, 1 \mathrm{H}, \mathrm{CH}), 7.00(\mathrm{~d}, 1 \mathrm{H}, J=8.0 \mathrm{~Hz}, \mathrm{CH}), 6.79$ $(\mathrm{d}, 1 \mathrm{H}, J=4.0 \mathrm{~Hz}, \mathrm{CH}), 6.85(\mathrm{~s}, 1 \mathrm{H}, \mathrm{CH}), 7.22(\mathrm{~d}, 1 \mathrm{H}, J=4.0 \mathrm{~Hz}, \mathrm{CH}) .{ }^{13} \mathrm{C}-\mathrm{NMR}\left(\mathrm{D}_{2} \mathrm{O}, t\right.$-butyl alcohol was added as an internal reference): $\delta=36.46,55.33,118.35,118.60,122.52,125.70,138.08$, 151.37, 172.74. Elemental analysis: calculated for $\mathrm{C}_{9} \mathrm{H}_{12} \mathrm{O}_{3} \mathrm{~N}_{2} .2 \mathrm{HCl} . \mathrm{CH}_{3} \mathrm{COCH}_{3} . \mathrm{C}, 44.05 \%$; $\mathrm{H}$, $6.16 \%$; N, 8.56\%; Cl, 21.67\%; found: C, 44.77\%; H, 5.98\%; N, 8.49\%; Cl, 20.47\%. UV (0.1 M HCl) $\lambda_{\max } 215 \mathrm{~nm}(\varepsilon 6,840)$ and $275 \mathrm{~nm}(\varepsilon 2,370)$.

\section{Conclusions}

A general procedure for the synthesis of 4-amino-3-hydroxy- and 3-amino-4-hydroxyphenyl derivatives 8c-13c was established based on the reduction of the nitro group to amine on the aromatic ring using $57 \% \mathrm{HI} / \mathrm{H}_{3} \mathrm{PO}_{2}$. This method is more convenient and generally applicable compared with other methods reported in the literature. Some degradation products of human NMs, SN-NM and LC-NM, were identified with these newly synthesized $o$-aminophenol compounds in HPLC determinations: the reductive $\mathrm{HI}$ hydrolysis of SN-NM and LC-NM afforded AHPEAs 8c, 9c, AHPAAs 10c, 11c, AHEBs 12c, 13c and AHPs 14c, 15c as degradation products. Then, by using this new degradative approach, we have found that SN-NM and LC-NM are derived not only from DA and NE, but also from several other catecholic precursors which are present in catecholaminergic neurons.

\section{Acknowledgments}

This work was supported in part by a Japan Society for the Promotion of Science (JSPS) KAKENHI Grant number 24500450 and in part by the Italian Ministry of Education, University, and Research (MIUR) - Medical Research in Italy (MERIT) Project RBNE08ZZN7. Authors also thank the Section of Legal Medicine and Insurances, Department of Human Morphology and Biomedical Sciences, University of Milano, for providing brain tissues. 


\section{Author Contributions}

Conceived and designed the experiments: KW, SI. Performed the experiments: HT, KT, SI. Analyzed the data: HT, KT, MO, SI. Prepared neuromelanin samples: FZ, LZ. Wrote the paper: KW, SI.

\section{Conflicts of Interest}

The authors declare no conflict of interest.

\section{References}

1. Ito, S.; Wakamatsu, K. Quantitative analysis of eumelanin and pheomelanin in humans, mice, and other animals: A comparative review. Pigment Cell Res. 2003, 16, 523-531.

2. Ito, S.; Wakamatsu, K. Chemistry of melanins. In The Pigmentary System. Physiology and Pathophysiology, 2nd ed.; Nordlund, J.J., Boissy, R.E., Hearing, V.J., King, R.A., Oetting, W.S., Ortonne, J.P., Eds.; Blackwell Publishing: Oxford, UK, 2006; pp. 282-310.

3. Simon, J.D.; Peles, D.N. The red and the black. Acc. Chem. Res. 2010, 43, 1452-1460.

4. Marsden, C.D. Pigmentation in the nucleus substantiae nigrae of mammals. J. Anat. 1961, 95, 256-261.

5. Zucca, F.A.; Basso, E.; Cupaioli, F.A.; Ferrari, E.; Sulzer, D.; Casella, L.; Zecca, L. Neuromelanin of the human substantia nigra: An update. Neurotox. Res. 2013, 25, 13-23.

6. Wakamatsu, K.; Fujikawa, K.; Zucca, L.; Zecca, L.; Ito, S. The structure of neuromelanin as studied by chemical degradative methods. J. Neurochem. 2003, 86, 1015-1023.

7. Wakamatsu, K.; Murase, T.; Zucca, F.A.; Zecca, L.; Ito, S. Biosynthetic pathway to neuromelanin and its aging process. Pigment Cell Melanoma Res. 2012, 25, 792-803.

8. Zecca, L.; Costi, P.; Mecacci, C.; Ito, S.; Terreni, M.; Sonnino, S. Interaction of human substantia nigra neuromelanin with lipids and peptides. J. Neurochem. 2000, 74, 1758-1765.

9. Zecca, L.; Stroppolo, A.; Gatti, A.; Tampellini, D.; Toscani, M.; Gallorini, M.; Giaveri, G.; Arosio, P.; Santambrogio, P.; Fariello, R.G.; et al. The role of iron and copper molecules in the neuronal vulnerability of locus coeruleus and substantia nigra during aging. Proc. Natl. Acad. Sci. USA 2004, 101, 9843-9848.

10. Zecca, L.; Bellei, C.; Costi, P.; Albertini, A.; Monzani, E.; Casella, L.; Gallorini, M.; Bergamaschi, L.; Moscatelli, A.; Turro, N.J.; et al. New melanic pigments in the human brain that accumulate in aging and block environmental toxic metals. Proc. Natl. Acad. Sci. USA 2008, 105, 17567-17572.

11. Langston, J.W.; Forno, L.S.; Tetrud, J.; Reeves, A.G.; Kaplan, J.A.; Karluk, D. Evidence of active nerve cell degeneration in the substantia nigra of humans years after 1-methyl-4-phenyl-1,2,3,6tetrahydropyridine exposure. Ann. Neurol. 1999, 46, 598-605.

12. McGeer, P.L.; Itagaki, S.; Boyes, B.E.; McGeer, E.G. Reactive microglia are positive for HLA-DR in the substantia nigra of Parkinson's and Alzheimer's disease brains. Neurology 1988, $38,1285-1291$. 
13. Zecca, L.; Wilms, H.; Geick, S.; Claasen, J.H.; Brandenburg, L.O.; Holzknecht, C.; Panizza, M.L.; Zucca, F.A.; Deuschl, G.; Sievers, J.; et al. Human neuromelanin induces neuroinflammation and neurodegeneration in the rat substantia nigra: Implications for Parkinson's disease. Acta Neuropathol. 2008, 116, 47-55.

14. Zhang, W.; Phillips, K.; Wielgus, A.R.; Liu, J.; Albertini, A.; Zucca, F.A.; Faust, R.; Qian, S.Y.; Miller, D.S.; Chignell, C.F.; et al. Neuromelanin activates microglia and induces degeneration of dopaminergic neurons: Implications for progression of Parkinson's disease. Neurotox. Res. 2011, $19,63-72$.

15. Cebrián, C.; Zucca, F.A.; Mauri, P.; Steinbeck, J.A.; Studer, L.; Scherzer, C.R.; Kanter, E.; Budhu, S.; Mandelbaum, J.; Vonsattel, J.P.; et al. MHC-I expression renders catecholaminergic neurons susceptible to T-cell-mediated degeneration. Nat. Commun. 2014, 5, 3633.

16. Ito, S.; Fujita, K. Microanalysis of eumelanin and pheomelanin in hair and melanomas by chemical degradation and liquid chromatography. Anal. Biochem. 1985, 144, 527-536.

17. Ito, S.; Wakamatsu, K. Chemical degradation of melanins: Application to identification of dopamine-melanin. Pigment Cell Res. 1998, 11, 120-126.

18. Wakamatsu, K.; Ito, S.; Rees, J.L. Usefulness of 4-amino-3-hydroxyphenylalanine as a specific marker of pheomelanin. Pigment Cell Res. 2002, 15, 225-232.

19. Ito, S.; Nakanishi, Y.; Valenzuela, R.K.; Brilliant, M.H.; Kolbe, L.; Wakamatsu, K. Usefulness of alkaline hydrogen peroxide oxidation to analyze eumelanin and pheomelanin in various tissue samples: Application to chemical analysis of human hair melanins. Pigment Cell Melanoma Res. 2011, 24, 605-613.

20. d'Ischia, M.; Wakamatsu, K.; Napolitano, A.; Briganti, S.; Garcia-Borron, J.-C.; Kovacs, D.; Meredith, P.; Pezzella, A.; Picardo, M.; Sarna, T.; et al. Melanins and melanogenesis: Methods, standards, protocols. Pigment Cell Melanoma Res. 2013, 26, 616-633.

21. Wakamatsu, K.; Ohtara, K.; Ito, S. Chemical analysis of late stages of phaeomelanogenesis: Conversion of dihydrobenzothiazine to a benzothiazole structure. Pigment Cell Melanoma Res. 2009, 22, 474-486.

22. Ito, S.; Fujita, K.; Yoshioka, M.; Sienko, D.; Nagatsu, T. Identification of 5-S- and 2-S-cysteinyldopamine and 5-S-glutathionyldopamine formed from dopamine by high-performance liquid chromatography with electrochemical detection. J. Chromatogr. Biomed. Appl. 1986, 375, 134-140.

23. Ito, S.; Kato, T.; Fujita, K. Covalent binding of catechols to proteins through the sulphydryl group. Biochem. Pharmacol. 1988, 37, 1707-1710.

24. Cartolano, A.R.; Vedage, G.A. Amines by reduction. In Kirk-Othmer Encyclopedia of Chemical Technology; John Wiley \& Sons, Inc: Hoboken, NJ, USA, 2004; doi:10.1002/0471238961.0113091419030809.a01.pub2.

25. Scheme, B.G.R. Béchamp Reduction. In Comprehensive Organic Name Reactions and Reagents; John Wiley \& Sons, Inc: Hoboken, NJ, USA, 2010; pp. 284-287.

26. Sajiki, H.; Hattori, K.; Hirota, K. The formation of a novel Pd/C-ethylenediamine complex catalyst: Chemoselective hydrogenation without deprotection of the $O$-benzyl and $\mathrm{N}$-Cbz groups. J. Org. Chem. 1998, 63, 7990-7992. 
27. Shafiee, A.; Parang, K.; Khaza, M.; Ghasemian, F. Nitroimidazoles X. Syntheses of substituted 2-(1-methyl-5-nitro-2-imidazolyl) quinolines. J. Heterocycl. Chem. 2009, 29, 1859-1861.

28. Engelen, M.; Vanna, R.; Bellei, C.; Zucca, F.A.; Wakamatsu, K.; Monzani, E.; Ito, S.; Casella, L.; Zecca, L. Neuromelanins of human brain have soluble and insoluble components with dolichols attached to the melanic structure. PLoS One 2012, 7, e48490.

Sample Availability: Samples of the compounds 8-13 are available from the authors.

(C) 2014 by the authors; licensee MDPI, Basel, Switzerland. This article is an open access article distributed under the terms and conditions of the Creative Commons Attribution license (http://creativecommons.org/licenses/by/3.0/). 